\title{
PLANTAS TÓXICAS EN LOS JARDINES DE LA CIUDAD DE TACNA
}

Rosario E. Zegarra ${ }^{1}$

\author{
RESUMEN
}

Las plantas ornamentales cultivadas en parques y jardines de la ciudad de Tacna y alrededores son relativamente baratas y fáciles de obtener. Con un cuidado moderado pueden brindarnos por muchos años esa belleza y estética vegetal. Existe una gran diversidad de especies y variedades de plantas ornamentales en Tacna, cuyos estudios previos han sido anteriormente publicados en la presente revista en 1995.

En este nuevo trabajo, sin embargo, se hace un enfoque panorámico del origen, principales características agrobotánicas y del sistema de reproducción de cerca de veinte especies fanerógamas ornamentales, consideradas como plantas tóxicas debido a que en algunas circunstancias son peligrosas para la salud.

Estas especies son mayormente cultivadas por su aspecto ornamental en los parques y jardines de la ciudad de Tacna y alrededores. Taxonómicamente han sido clasificadas en trece familias y su descripción agrobotánica está orientada a la identificación fácil y rápida, que a pesar de la atracción y valor estético que poseen, es oportuno y saludable conocer sus características particulares para prevenir posibles intoxicaciones.

\section{A B S TRACT}

Ornamental plants grown in the parks and gardens in the city of Tacna and outskirts are relatively inexpensive and easy to obtain. With only moderate care, they are long lasting and so economical. They are available in a wide range of shapes, sizes, colors, and types. Their care is a matter of both natural and acquired skills and sensitivities and their use as decoration is an exercise of taste and personality. Anyone who looks after a plant in a garden or park for a period of time cannot fail to become.interested in its development, in each new leaf that unfurls and each new flower that opens. More than forty ornamental plants has been already described for Tacna and previously published in 1995 in this scientific journal. There are many decorative species, however, which are considered as toxic plants when accidentally are eaten or closely in contact with their latex or exsudants. About twenty botanical species grouped in 13 taxonomic families have been identified and described using morphological characters for its easy identification. All plants have been given popular names, but they sometimes differ from country to country, even from region to region. 


\section{INTRODUCCIÓN}

Por su belleza, las plantas y flores nos rodean en la casa, en la oficina, en los parques y jardines. Sin embargo, algunas especies ornamentales son tóxicas. Algunas familias tienen más especies venenosas, que otras. De una especie tóxica, algunas partes o tejidos de la planta pueden ser venenosas mientras que otras no. No obstante, plantas que son muy comunes y no se conocen como tóxicas, pueden convertirse en venenosas bajo ciertas circunstancias, por ejemplo, cuando acumulan sustancias tóxicas extraídas del suelo. Los estudios filogenéticos indican que, generalmente, las sustancias tóxicas protegen a las plantas contra el ataque de insectos y otras plagas que han evolucionado como mecanismos de protección y defensa. En la mayoría de las especies venenosas, la acción de las sustancias tóxicas es desconocida. En el presente trabajo se da a conocer las principales especies tóxicas cultivadas en los parques y jardines, con el objeto que sean conocidas.

\section{MATERIAL Y MÉTODOS}

El material que ha servido de base para este estudio son los parques y jardines de la ciudad de Tacna y distritos cercanos a la capital provincial. El material más importante de este trabajo es la colección de especímenes vegetales, los cuales se prepararon investigarón, haciendo uso de claves botánicas, obras especializadas y por comparación. Se identificaron 20 especies conocidas como tóxicas para la ciudad de Tacna y alrededores. Entre las gimnospermas se encuentra una sola especie. Las angiospermas están representadas por 13 familias, de las cuales las euforbiáceas y apocináceas con 3 especies cada una, las aráceas y arillidáceas con 2, papaveráceas, fabáceas, saxifagáceas, oleáceas, araliáceas, verbenáceas, salanáceas, convolvuláceas y lamiáceas con una especie cada una. Las ilustraciones que acompañan al presente artículo fueron realizadas con ejemplares de herbario y en algunos casos con plantas frescas.

\section{III.TRATAMIENTO SISTEMÁTICO}

\section{I. SUBDIVISIÓN GIMNOSPERMAS}

\section{Familia Cupressaceae}

1) Thuja L sp. "Tuja" o " tuya"

Especies monoicas. Árboles o arbustos con ramas plegadas.

Hojas escamiformes, opuestas, decusadas.

Los amentos masculinos terminales. Flores con numerosas hojas polínicas, opuestas con 2-4 sacos polínicos cada una.
Estróbilos femeninos oblongos u ovoides, conformados por 6-12 escamas opuestas. Óvulos 1-3 por escama fértil.

Los conos subleñosos, deshicentes.

Semillas ápteras o aladas.

Las dos especies cultivadas en Tacna Thuja occidentalis y Thuja orientalis, presentan partes tóxicas en la madera, extremo de las ramas y en los frutos, al contener tuyina y tuyugina.

Propagación : por semilla botánica.

\subsection{SUBDIVISIÓN ANGIOSPERMAS}

\section{A. MONOCOTILEDÓNEAS}

\section{Familia Araceae}

2) Dieffenbachia amoena . "Lluvia de plata"

Nativa de Brasil

Perenne.

Hojas grandes pecioladas, de ápice agudo, penninervias. El limbo con manchas de color blanco. Inflorescencia : espádice compacto, protegido por una esopata bien desarrollada, herbácea o carnosa.

Flores masculinas dispuestas en la porción superior del espádice, con ausencia de perianto.

Flores femeninas en la región basal.

Fruto : baya globosa, con el estigma persistente.

Parte tóxica : la savia que se encuentra en los tallos $y$ hojas.

Si se mastican estas partes se produce ardor e irritación en boca y garganta, inflamando la lengua. Propagación por esquejes.

3) Philodendron scandens. "Filodendro", "boa"

Oriunda de las Antillas (Puerto Rico).

Especie voluble, con largas raíces adventicias, hojas sagitadas, grandes, largamente pecioladas, limbo entero.

Inflorescencia : en espádice protegida por una espata bien desarrollada, verdosa.

Flores diclino-monoicas. Las masculinas compuestas por 2-6 estambres sésiles.

Flores femeninas, con el ovario súpero, pluriovulados.

Fruto : una baya

Parte tóxica: las hojas causan irritación en las mucosas, provocando náuseas y vómitos.

Propagación: por esquejes apicales o esquejes que tienen segmentos de tallos con algunos nudos. 


\section{Familia Amarillidaceae}

4) Crinum asiaticum L. "Lirio o azucena"

Especie asiática bulbosa, hojas arrosetadas de 0,90 por $1,20 \mathrm{~m}$. de largo, por $5-10 \mathrm{~cm}$. de ancho, lanceoladas, acuminadas, paralelinervias.

Escapo floral macizo, llevando una inflorescencia umbeliforme pluriflora.

Flores pedunculadas blancas. Androceo con 6 estambres rojizos y anteras amarillas.

Ovario ínfero tricarpelar

Fruto capsular.

Parte tóxica : el bulbo.

Propagación : mediante bulbos

5) Narcissus tazetta. "Junco común" o "blanco".

Planta herbácea y bulbosa, de tamaño pequeño, hojas lineales, planas de $30-5 \mathrm{~cm}$. de largo.

Inflorescencia : umbelar que nace en la extremidad de un escapo floral largo.

Perigonio con 6 tépalos con segmentos blancos, corona blanca o amarilla.

Estambres 6. Ovario infero trilocular

Fruto capsular dehiscente por 3 valvas.

Origen: Islas Canarias, Europa y Asia.

Parte tóxica : el bulbo. Causa náuseas, vómitos, temblores, convulsiones, diarrea.

Propagación : mediante bulbos

\section{B. CLASE DICOTILEDÓNEAS}

\section{Familia Papaveraceae}

6) Papaver rhoeas L. "Amapola de jardín"

Especie anual, caulescente, con hojas basales y caulinares.

Hojas simples no abrazadoras, pinnatífidas con los lóbulos lanceolados, aserrados.

Flores con el pedúnculo floral con pelos hirsutos.

Actinomorfas, hermafroditas. Sépalos 2 caducos.

Pétalos 40 muchos. Estambres numerosos, ovario súpero pluriovulado, estigmas sésiles, verticilados.

Fruto: Cápsula dehiscente, poricida.

Nativa de Europa y Asia.

Parte tóxica : el tallo contiene el alcaloide tóxico rhoedina.

Propagación : por semilla botánica.

\section{Familia Fabaceae}

7) Sparthium junceum L. "Retama"

Arbusto oriundo del Mediterráneo (España, Italia). Mide hasta $2 \mathrm{~m}$ de altura, subáfilo, ramas pequeñas verdes, hojas unifoliadas, pequeñas, algo pecioladas. Inflorescencia en racimo, con gran número de flores papilionadas.

Cáliz pequeño espatáceo. Corola amarillo-dorada.

Estambres monodelfos. Gineceo con ovario súpero.

Fruto: Legumbre o vaina de $6-7 \mathrm{~cm}$ de longitud bivalva, polisperma.

Parte tóxica: En flores, semillas, todas las partes de la planta contienen el alcaloide citisina (muy tóxico).

Propagación : por semilla botánica.

\section{Familia Euphorbiaceae}

8) Euphorbia pulcherrina Willd. "Corona del Inca", "cardenal", "flor de Navidad", "estrella de Navidad". Especie arbustiva lacitífera. Hojas simples, alternas. Flores reunidas en pequeños ciatos, con una flor femenina central y varias masculinas reducidas a un solo estambre articulado.

Los ciatos protegidos por brácteas o hipsófilos de colores llamativos : rojo, amarillo, o anaranjado, dando la impresión de ser éstas las flores.

Fruto : cápsula tricoca

Nativa de México.

Parte tóxica : el látex que discurre por toda la planta. Propagación : por esquejes.

9) Croton variegatum (L.) Blume. "Croton"

Originaria del sur de la India y Ceilán a través de Malaya hasta las islas Sunday.

Arbusto decorativo. Hojas simples, alternas, de color variado, polimorfas.

Inflorescencia en espiga larga. Flores pequeñas y poco llamativas.

Con innumerables formas hortícolas.

Parte tóxica : Ias hojas. Irritan las mucosas.

Propagación : por esquejes en brotes terminales

10) Ricinus communis L. "Higuerilla, ricino tártago" Nativa de África.

Arbustiva monoica. Tallo erguido, grueso, verde rojizo.

Hojas simples, alternas, largamente pecioladas, palmatihendidas, aserradas, glabras 
Inflorescencia : en racimo, flores acompañadas de brácteas pequeñas, membranáceas.

Las flores masculinas en la parte inferior, con estambres arborescentes. Las flores femeninas en la parte apical, con ovario globuloso erizado súpero 3-locular, con un óvulo en cada lóculo, el estilo terminado por tres estigmas bífidos.

Fruto: cápsula ovoide, erizada

Semillas carunculadas con testa matizada, color café claro y oscuro.

Parte tóxica : de sus semillas se obtiene el aceite de ricino Contienen una fitotoxina llamada ricina, sumamente tóxica. Hojas y semillas poseen alcaloides asociados con proteínas.

Propagación : por semillas.

\section{Familia Saxifragaceae}

11) Hydrangea macrophylla (Thunb) DC. "Hortensia".

Arbusto ramificado, nativo de Japón. Mide 1-1.5 m de altura.

Hojas simples, opuestas, elípticas o aovadas, aserradas, brevemente acuminadas.

Inflorescencia : cimosa corimbiforme muy grande y vistosa.

Flores hermafroditas o estériles. Cáliz 4-5 petaloideos. Corola 4-5 con pétalos pequeños blanco, rosado y celeste. Androceo 8-20 estambres exertos.

Ovario ínfero o flor perigina.

Flores total o parcialmente estériles .

Fruto capsular

Parte tóxica: la savia, ligeramente, por lo general las intoxicaciones suelen ser leves.

Se multiplican por esquejes.

\section{Familia Araliaceae}

12) Hedera helix L. "Hiedra"

Especie trepadora, originaria de la cuenca del Mediterráneo. Con raíces adventicias mediante las cuales se adhiere a otras plantas o muros.

Hojas simples, alternas, palmatihendidas, borde entero, lustrosas.

Inflorescencia : en umbela.

Flores actinomorfas, hermafroditas o polígamas muy pequeñas.

Corola con 5 pétalos, estambres 5 en igual número al de los pétalos. Ovario ínfero generalmente bilocular.
Fruto Drupa.

Parte tóxica : tallo, hojas, frutos. Intoxicaciones poco frecuentes.

Propagación : por esquejes.

\section{Familia Apocinaceae}

13) Nerium oleander L. "Laurel rosa", "adelfa"

Originaria del Mediterráneo oriental.

Arbusto laticífero de 1-1.5 m de altura. Hojas coriáceas simples, verticiladas, lanceoladas, margen entero, penninervias.

Inflorescencia : cimosa. Flores actinomorfas, hermafroditas.

Cáliz 5, corola gamopétala, pentalobulada con 5 o más pétalos de color blanco o rosado. Estambres 5 epicarolinos. Ovario súpero bicarpelar

Fruto : Cápsula con semillas aladas.

Parte tóxica : una de las especies más tóxicas, principalmente sus semillas.

Si se consumen las hojas o los frutos puede, causar intoxicación. Esto se presenta en niños y animales que accidentalmente ingieren los frutos o muerden las hojas.

Propagación: por estacas o por división de matas.

14) Catharanthus roseus L. "Isabelita", "panchita", "pervinca"

Procede de Madagascar. Son especies cosmopolitas.

Planta pequeña, erguida, herbácea, puede echar retoños en la base.

Hojas simples, alterna, oblongas, color verde oscuro, margen entero, penninervias.

Flores solitarias ascilares. Cáliz 5 pequeño.

Corola hipocrateriforme, se abre formando $5 \mathrm{limbos}$ espatulados y divididos: Estambres 5 epicorolinos.

Gineceo : ovario súpero bicarpelar.

Fruto : capsular alargado

Usada como medicinal. Con propiedades anticancerígenas. Contiene gran cantidad de alcaloides.

El consumo de sus hojas maduras sin prescripción facultativa puede ser fatal.

Propagación : por esquejes y semilla botánica.

15) Thevetia peruviana (Pers.) Schum. "Ciática", "bellaquillo".

Nativa del Perú. Árbol llamativo, 2m. de altura.

Hojas simples, alternas, lanceoladas, ápice 
acuminado, penninervias.

Flores solitarias axilares.

Cáliz 5. Corola 5, pétalos amarillos unidos.

Androceo: 5 estambres epicorolinos. Ovario súpero bicarperlar.

Fruto capsular.

Parte tóxica: contiene cantidades peligrosas de un glucósido tóxico (thevetina). El látex y las semillas son venenosos.

Propagación : por semilla botánica.

\section{Familia Oleaceae}

16) Ligustrum vulgare $L$. "Ligustro"

Árbol pequeño, nativo de Europa y norte de África, muy cultivado como cerco vivo.

Hojas simples opuestas, lanceoladas, acuminadas, margen entero, penninervias.

Inflorescencia: Racimos compuestos, conformados por un gran número de pequeñas flores de prefloración valvada. Cáliz 4. Corola 4 pétalos blancos. Estambres 2 epipétalos. Gineceo con ovario súpero bilocular.

Fruto drupáceo, pequeño, de color negro.

Parte tóxica : la especie contiene glucósidos .

La ingestión de partes aéreas de la planta causa vómitos y diarrea.

Propagación : por estacas y semilla botánica

\section{Familia Verbenaceae}

17) Lantana camara L. "Lantana"

Especie arbustiva o semileñosa. Hojas simples, opuestas, ovoides, dentadas, ásperas, arrugadas con envés tormentoso.

Flores pequeñas de color amarillo, rosado, rosa o naranja, las flores se abren sucesivamente hacia el centro, reunidas en capítulos axilares.

Flor hermafrodita, zigomorfa.

Corola 5 pétalos .Gineceo con ovario súpero.

Fruto drupáceo de color negro,

Nativa de Sudamérica y Argentina.

Parte tóxica : los frutos contienen lantodene, causante de irritación gastrointestinal con dolor y diarrea.

Sus hojas son venenosas, por la presencia de alcaloides.

Actualmente se emplea como planta biocida y repelente para insectos como la polilla.

Propagación : por estacas y semilla botánica.

\section{Familia Solanaceae}

18) Brugmansia candida (Persoon). "Floripondio"

Especie nativa de Sudamérica. Arbórea, pequeña, conocida anteriormente como Datura candida.

Tallo con ramas péndulas.

Hojas simples alternas, aovado lanceoladas, oblongas y aovadas, asimétricas, pubescentes.

Flores solitarias axilares muy grandes y vistosas de color blanco y rosado. Cáliz tubuloso espatulado.

Corola infundibiliforme. Pétalos blancos. Estambres 5 inclusos epicorolinos. Gineceo con ovario súpero bicarpelar.

Fruto capsular.

Parte tóxica : sus hojas son tóxicas. Estas plantas contienen alcaloides. Puede presentarse diarrea, dilatación de pupilas, rigidez del cuerpo.

Se multiplica por esquejes y semilla botánica.

\section{Familia Convolvulaceae}

19) Ipomoea purpúrea L. "Campanilla".

Oriunda de América tropical.

Especie voluble, amical.

Hojas simples alternas, cordiformes.

Flores solitarias ascilares que se abren al amanecer.

Cáliz 5 sépalos. Corola acampanada, 5 pétalos lobulados azules o purpúreos, estambres 5 epicorolinos.

Gineceo con ovario súpero 2-3 carpelos

Fruto capsular esférico.

Parte tóxica : Sus semillas contienen alcaloides como argina, isoergina y otros.

Propagación : por semilla botánica.

\section{Familia Lamiaceae}

20) Leonotis nepetaefolia. "Cordón de fraile"

Especie arvense, sobrepasa el metro de altura. Hojas elípticas, opuestas, aserradas, penninervias. Inflorescencia: Flores reunidas en nudos verticilados, zigomorfas, hermafroditas.

Sépalos 5 persistentes. Corola labiada anaranjada. Estambre 4, didínamos. Ovario súpero tetralobulado. Fruto: aquenio

Parte tóxica: fuente de irritación a personas alérgicas a ella (aceites volátiles, venenosos).

Propagación : por semilla botánica. 

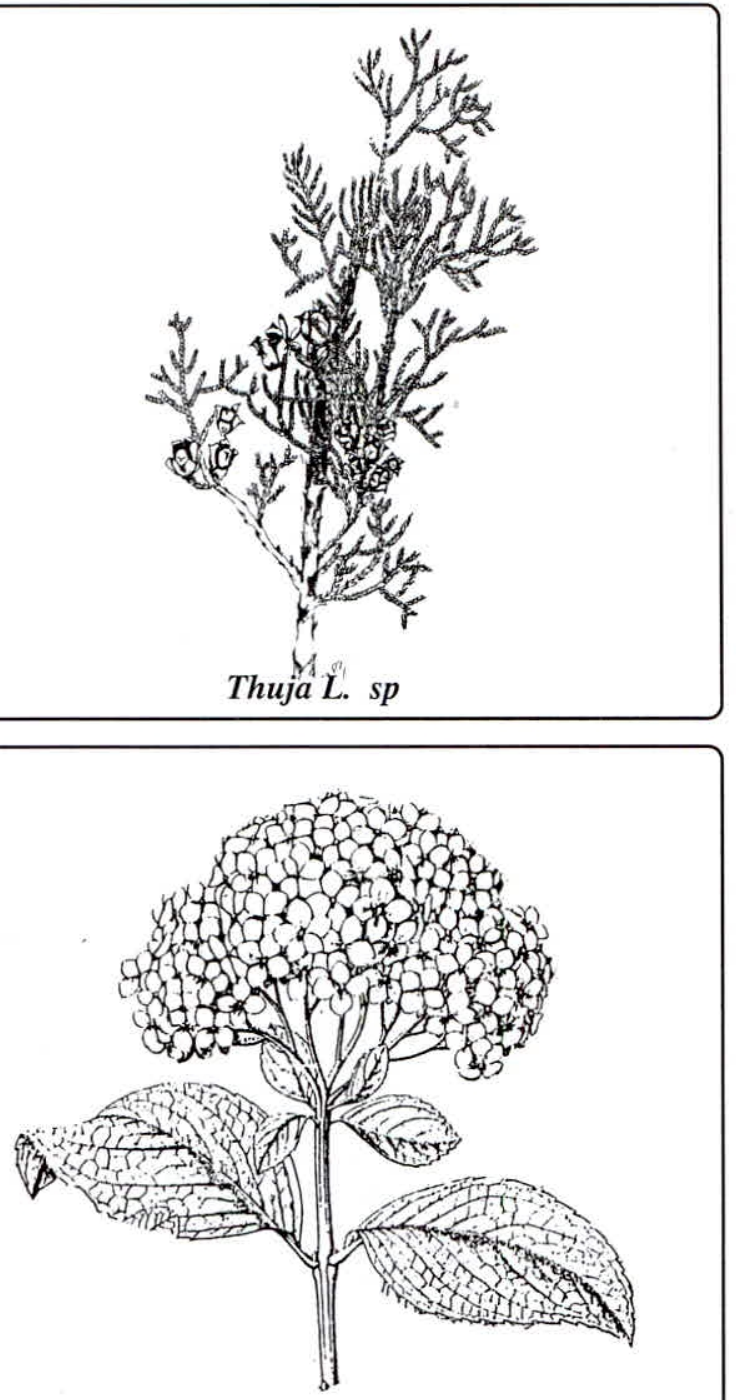

Hydrangea macrophylla (Thumb) DC.

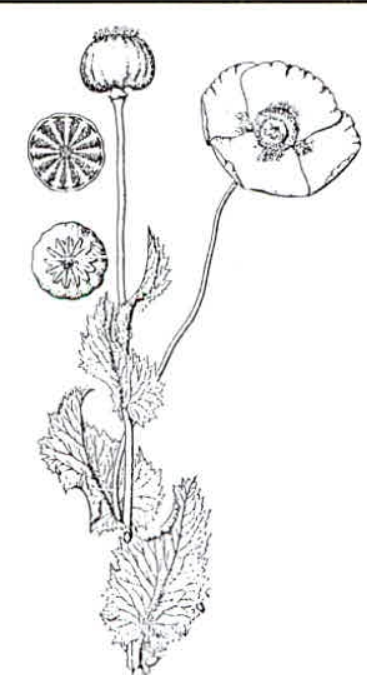

Papaver rhoeas $L$.

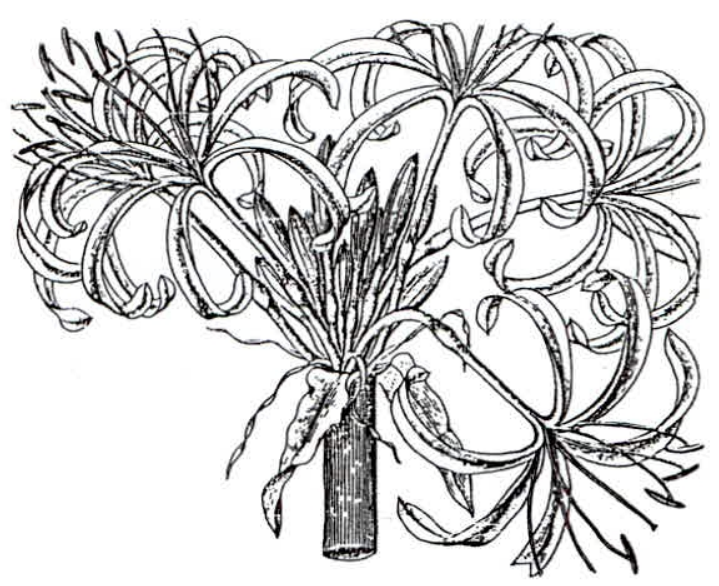

Crinum asiaticum $L$.

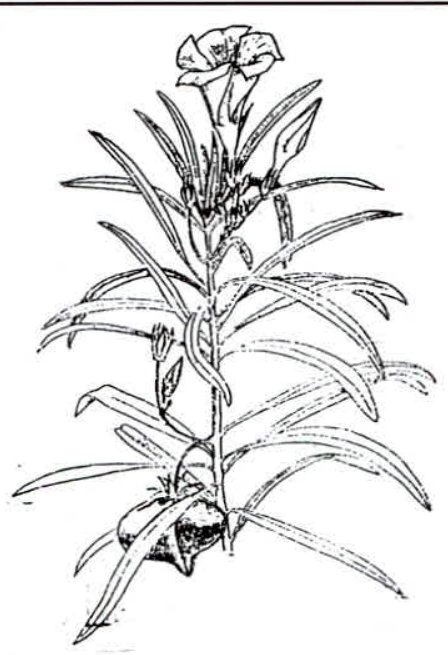

Thevetia peruviana (Pers.) Schum

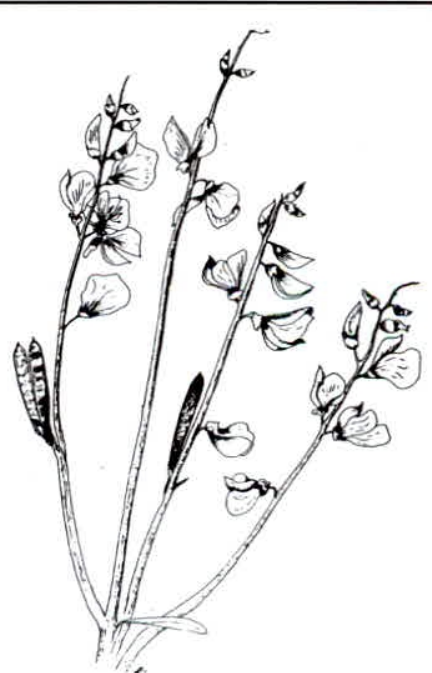

Spartium junceum $L$. 


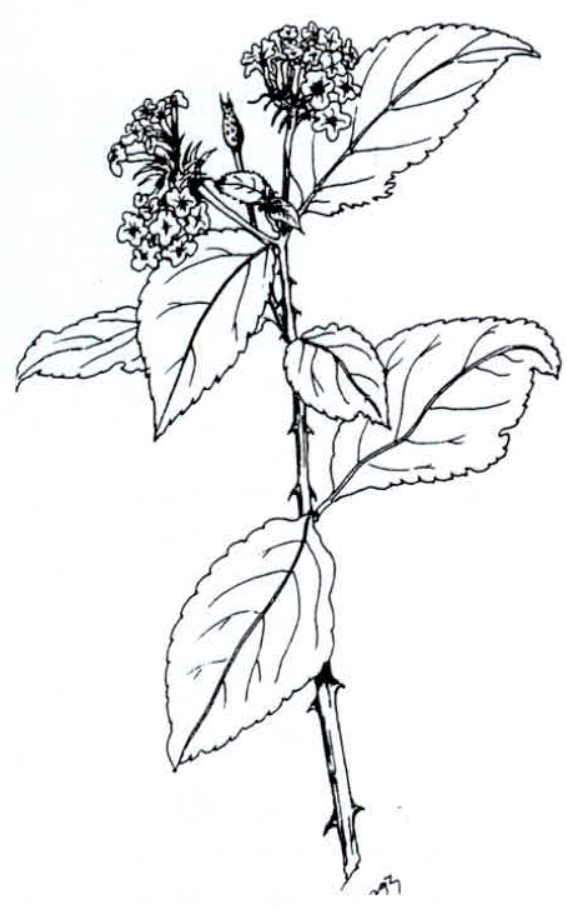

Lantana camara $L$.

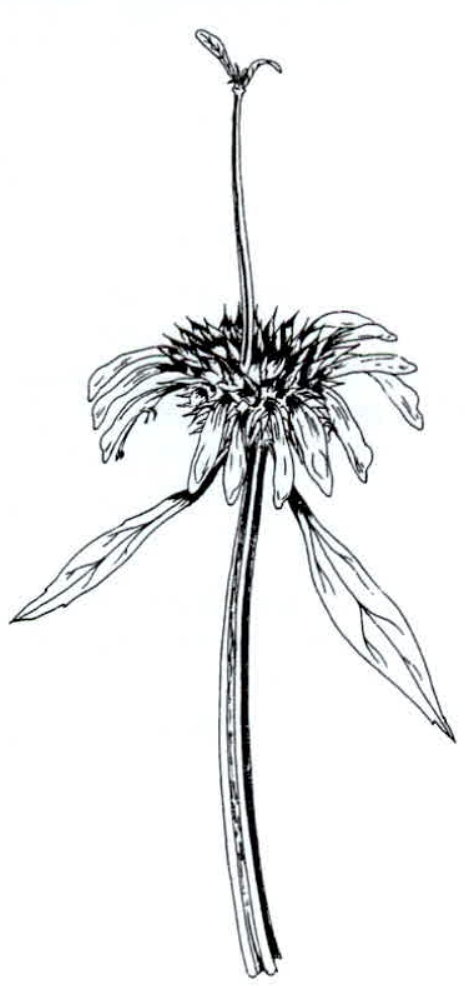

Leonotis nepetaefolia

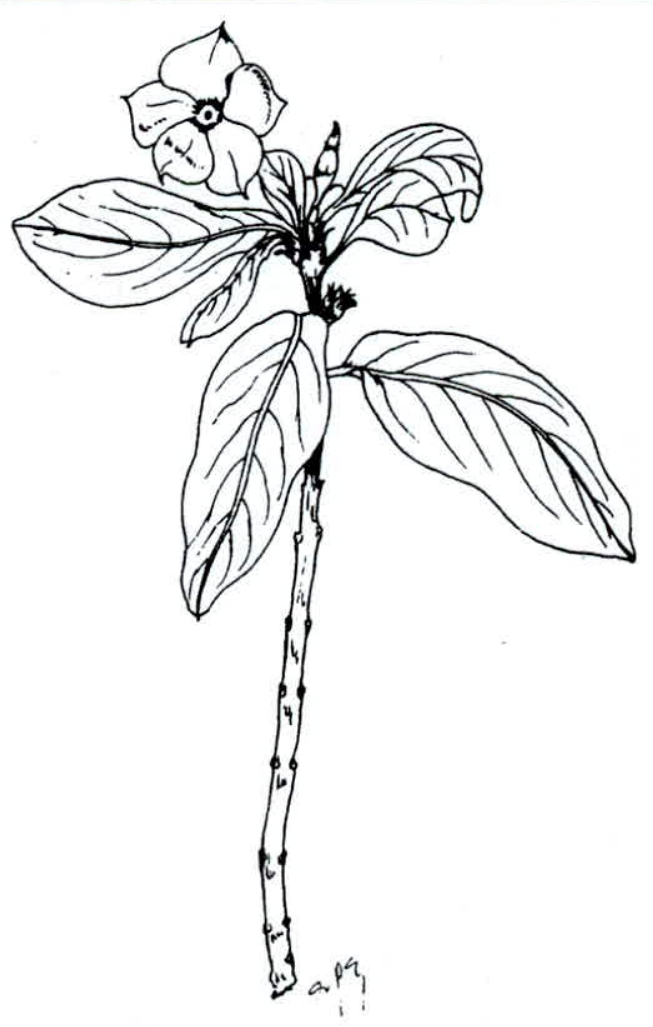

Catharanthus roseus $L$.

IV. BIBLIOGRAFÍA

Kramer, Jack ( 1981). Flowering Houseplants Salamander Book London

Pizetti, Mariella ( 1985). Plantas de interior. España.

Strasburger, E., y otros (1986). Tratado de Botánica, Ed. Marín S.A., España.

Zegarra, R. (1995). Plantas ornamentales de la ciudad de Tacna, revista Ciencia y Desarrollo Nro.2, UNJBG Tacna-Perú. 